\title{
Correction: Lee, J. et al. Acute Effects of Exposure to a Traditional Rural Environment on Urban Dwellers: A Crossover Field Study in Terraced Farmland. Int. J. Environ. Res. Public Health 2015, 12, 1874-1893
}

\author{
Juyoung Lee ${ }^{1, \dagger}{ }^{\text {, Bum-Jin Park }}{ }^{2,+}$, Tatsuro Ohira ${ }^{3,+}$, Takahide Kagawa ${ }^{3,+}$ (i) and \\ Yoshifumi Miyazaki ${ }^{4, *(\mathbb{C}}$ \\ 1 Korea Forest Service, Government Complex 1, 189 Cheongsa-Ro, Seo-Gu, Daejeon 302-701, Korea; \\ lohawi@gmail.com \\ 2 Department of Environment and Forest Resources, Chungnam National University, 99 Daehak-ro, \\ Yuseong-gu, Daejeon 34134, Korea; bjpark@cnu.ac.kr \\ 3 Forestry and Forest Products Research Institute, 1 Matsunosato, Tsukuba, Ibaraki 305-8687, Japan; \\ otatsu@ffpri.affrc.go.jp (T.O.); kagawa@ffpri.affrc.go.jp (T.K.) \\ 4 Center for Environment, Health and Field Sciences, Chiba University, 6-2-1 Kashiwa-no-ha, Kashiwa, \\ Chiba 277-0882, Japan \\ * Correspondence: ymiyazaki@faculty.chiba-u.jp; Tel.: +81-4-7137-8113; Fax: +81-20-4666-0398 \\ $\dagger$ These authors contributed equally to this work.
}

Received: 24 June 2019; Accepted: 26 September 2019; Published: 11 December 2019

The authors wish to add the following corrections to their paper published in the International Journal of Environmental Research and Public Health [1]. When calculating the T-score of Profile of Mood States (POMS) data, an error occurred. The following change should be made to Table 1, Figure 7 and its explanation in the published article. The change does not affect the conclusions of the article in any way.

Table 1 should be replaced with the following:

Table 1. Baseline values of the subjects in rural and urban environments.

\begin{tabular}{|c|c|c|c|c|c|}
\hline & \multicolumn{2}{|c|}{ Rural } & \multicolumn{2}{|c|}{ Urban } & \multirow{2}{*}{ Differences } \\
\hline & Mean & SE & Mean & SE & \\
\hline \multicolumn{6}{|c|}{ Physiological parameters } \\
\hline Pulse rate(bpm) & 59.1 & 3.0 & 61.5 & 3.6 & ns \\
\hline $\mathrm{SBP}(\mathrm{mmHg})^{\mathrm{a}}$ & 116.0 & 2.1 & 122.2 & 3.5 & ns \\
\hline $\mathrm{DBP}(\mathrm{mmHg})^{\mathrm{b}}$ & 61.7 & 1.9 & 64.1 & 2.0 & ns \\
\hline $\ln (\mathrm{HF})$ & 6.5 & 0.2 & 6.1 & 0.4 & ns \\
\hline $\ln (\mathrm{LF} / \mathrm{HF})$ & -2.3 & 0.7 & -3.1 & 0.8 & ns \\
\hline \multicolumn{6}{|c|}{ Psychological parameters } \\
\hline \multicolumn{6}{|l|}{ SD } \\
\hline Comfortable feeling & 2.5 & 0.5 & 1.5 & 0.5 & ns \\
\hline Soothed feeling & 1.9 & 0.7 & 2.3 & 0.7 & ns \\
\hline Natural feeling & -1.2 & 1.0 & -1.0 & 0.8 & ns \\
\hline Refreshed feeling & 47.5 & 5.0 & 52.7 & 4.1 & ns \\
\hline
\end{tabular}


Table 1. Cont.

\begin{tabular}{lccccc}
\hline & \multicolumn{2}{c}{ Rural } & \multicolumn{2}{c}{ Urban } & \multirow{2}{*}{ Differences } \\
\cline { 2 - 5 } & Mean & SE & Mean & SE & \\
\hline POMS & & & & & \\
\hline Tension-anxiety & 46.7 & 3.2 & 44.7 & 4.4 & ns \\
\hline Depression & 46.8 & 3.3 & 47.2 & 3.0 & ns \\
\hline Anger-hostility & 43.8 & 2.8 & 41.5 & 1.9 & ns \\
\hline Fatigue & 47.4 & 3.9 & 46.4 & 4.2 & ns \\
\hline Confusion & 47.5 & 2.7 & 49.4 & 3.8 & ns \\
\hline Vigor & 43.1 & 2.6 & 40.9 & 2.6 & $\mathrm{~ns}$ \\
\hline
\end{tabular}

Notes: ${ }^{a}$ SBP, systolic blood pressure; ${ }^{\mathrm{b}}$ DBP, diastolic blood pressure.

Figure 7 should be replaced with the following figure:

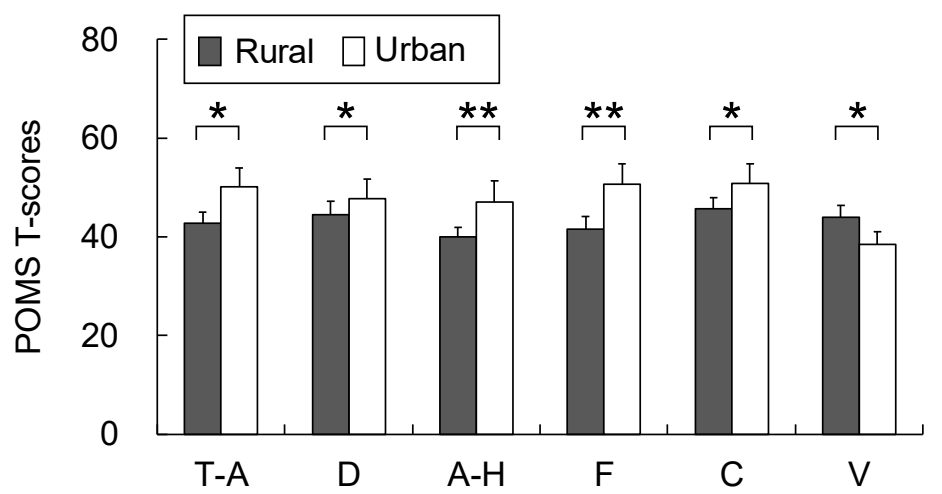

Figure 7. Comparison of the Profile of Mood States (POMS) scores after exposure to the rural and urban landscapes. Mean $\pm \mathrm{SE} ; \mathrm{N}=11 ;{ }^{*} p<0.05 ;{ }^{* *} p<0.01$; Wilcoxon signed-rank test. T-A, tension-anxiety; $\mathrm{D}$, depression; $\mathrm{A}-\mathrm{H}$, anger-hostility; $\mathrm{F}$, fatigue; $\mathrm{C}$, confusion; $\mathrm{V}$, vigor.

Lines $10-12$ on page 1880 should be replaced with the following text:

The T-score was used for the analysis of the POMS test.

The lines 24-27 in page 1883 should be changed as follows:

In the POMS analysis (Figure 7), significant differences were observed during the post-exposure period between the rural and urban environments, respectively, for all of the subscale scores including those for T-A $(42.7 \pm 2.3 ; 50.2 \pm 3.8 ; p<0.05)$, D $(44.5 \pm 2.8 ; 47.8 \pm 4.0 ; p<0.05)$, A-H $(40.1 \pm 1.7 ; 47.1 \pm 4.4$; $p<0.01), \mathrm{V}(44.0 \pm 2.3 ; 38.5 \pm 2.4 ; p<0.05), \mathrm{F}(41.5 \pm 2.6 ; 50.7 \pm 4.0 ; p<0.01)$, and $\mathrm{C}(45.6 \pm 2.2 ; 50.9 \pm 3.9 ; p$ $<0.05)$. However, no significant differences were observed in the baseline period values between the rural and urban environments, respectively: T-A $(46.7 \pm 3.2 ; 44.7 \pm 4.4), \mathrm{D}(46.8 \pm 3.3 ; 47.2 \pm 3.0), \mathrm{A}-\mathrm{H}(43.8 \pm$ $2.8 ; 41.5 \pm 1.9), \mathrm{V}(43.1 \pm 2.6 ; 40.9 \pm 2.6), \mathrm{F}(47.4 \pm 3.9 ; 46.4 \pm 4.2)$, and $\mathrm{C}(47.5 \pm 2.7 ; 49.4 \pm 3.8)$.

We apologize for any inconvenience caused to the readers by this error.

\section{Reference}

1. Lee, J.; Park, B.J.; Ohira, T.; Kagawa, T.; Miyazaki, Y. Acute effects of exposure to a traditional rural environment on urban dwellers: a crossover field study in terraced farmland. Int. J. Environ. Res. Public Health 2015, 12, 1874-1893. [CrossRef] [PubMed]

(C) 2019 by the authors. Licensee MDPI, Basel, Switzerland. This article is an open access article distributed under the terms and conditions of the Creative Commons Attribution (CC BY) license (http://creativecommons.org/licenses/by/4.0/). 